\title{
Stearoyl-coenzyme A desaturase 1 is required for lipid droplet formation in pig embryo
}

\author{
Dong-Kyung Lee ${ }^{1}$, Kwang-Hwan Choi ${ }^{1}$, Jae Yeon Hwang ${ }^{1,2}$, Jong-Nam Oh${ }^{1}$, Seung-Hun Kim ${ }^{1}$ \\ and Chang-Kyu Lee Le,3 $^{1,3}$ \\ ${ }^{1}$ Department of Agricultural Biotechnology, Animal Biotechnology Major, and Research Institute of Agriculture and \\ Life Science, Seoul National University, Seoul, Korea, ${ }^{2}$ Department of Cellular and Molecular Physiology, Yale School \\ of medicine, New Haven, Connecticut, USA and ${ }^{3}$ Institute of Green Bio Science and Technology, Seoul National \\ University, Pyeong Chang, Kangwon do, Korea
}

Correspondence should be addressed to C-K Lee; Email: leeck@snu.ac.kr

\begin{abstract}
Lipid droplets (LD) provide a source of energy, and their importance during embryogenesis has been increasingly recognized. In particular, pig embryos have larger amounts of intercellular lipid bilayers than other mammalian species, suggesting that porcine embryos are more dependent on lipid metabolic pathways. The objective of the present study was to detect the effect of stearoylcoenzyme A desaturase 1 (SCD1) on LD formation and to associate these effects with the mRNA abundance of LD formation-related genes (SREBP, ARF1, COPG2, PLD1 and ERK2) in in vitro-produced porcine embryos. To determine the effect of SCD1 on LD formation and related genes, we examined the effects of SCD1 inhibition using CAY10566 (an SCD1 inhibitor, 50 $\mu$ M) on parthenogenetic embryos. SCD1 inhibition downregulated the mRNA levels of LD formation-related genes and embryo development. Our results revealed that SCD1 functions in the regulation of LD formation via phospholipid formation and embryo development. In addition, we treated parthenogenetic embryos with oleic acid $(100 \mu \mathrm{M})$, which led to a significant increase in the blastocyst formation rate, LD size and number compared to controls. Remarkably, the adverse effects of the SCD1 inhibitor could be counteracted by oleic acid. These data suggest that porcine embryos can use exogenous oleic acid as a metabolic energy source.

Reproduction (2019) 157 235-243
\end{abstract}

\section{Introduction}

Mammalian oocyte-, egg- and cleavage-stage embryos rely almost exclusively on the metabolism of pyruvate and fatty acids (FAs) by mitochondria, which then produce energy in the form of ATP (Acton et al. 2004, Dumollard et al. 2008). FA metabolism is a major energy source for mitochondria and is particularly important in oocytes and preimplantation embryos. Lipid droplets (LDs) are unique organelles that store lipids and are essential for cellular energy and membrane production (Walther \& Farese 2012, Thiam et al. 2013). LDs consist of a neutral lipid core primarily composed of triglycerides coated with a phospholipid monolayer. The importance of LDs as an energy source during embryogenesis has been increasingly recognized. To grow, proliferate and survive, the embryo must evolve mechanisms to quickly respond to lipid requirements. Pig embryos in particular contain numerous large LDs as well as large amounts of intercellular lipid bilayers compared to other species, suggesting that porcine embryos are more dependent on lipid metabolic pathways (Leese 2012). Studies have reported that $L D$ degradation during embryo maturation can affect embryo development (Dunning et al. 2010,
Aardema et al. 2017). However, no studies have examined the development status of porcine embryos in relation to LD formation and degradation.

Previous studies have identified different populations of LDs in cells based on differences in their size, proteins and lipid composition (Wolins et al. 2005, Hsieh et al. 2012, Wilfling et al. 2013). LDs can be classified into two types according to size and stage of the LD life cycle. Initial LDs are formed in the endoplasmic reticulum (ER), presumably through a budding process, and appear to range from 300 to $600 \mathrm{~nm}$ in diameter (Wilfling et al. 2013). Initial LDs are thought to bud and detach from the ER in mammalian cells. A subset of initial LDs can be converted into expanding LDs with distinct protein compositions, including triglyceride synthesis enzymes that mediate their expansion (Wilfling et al. 2013). The ADP-ribosylation factor 1 (Arf1) and coatomer (a coat protein complex; COPI) machinery is required for this transition. Depletion of Arf1/COPI proteins from cells leads to the formation of relatively uniform LDs of a characteristic size that exhibit impaired lipolysis (Beller et al. 2008, Guo et al. 2008). We identified changes in coatomer subunit 
gamma-2 (COPG2), a COPI component, in response to CAY10566 and oleic acid (OA). Stearoyl-coenzyme A desaturase $(\mathrm{SCD})$ is responsible for converting saturated FAs into mono-unsaturated fatty acids (MUFAs) and also plays an important role in regulating FA composition. Although the number of SCD isoforms differs among species, SCD1 is a major isoform expressed in the lipogenic cells of all species studied to date (Hsieh et al. 2012). In addition, SCD1 plays an important role in regulating FA synthesis and metabolism by participating in multiple biological processes. FA metabolism appears to be essential for preimplantation development in all mammalian embryos (Sturmey et al. 2009), including those with relatively low lipid contents. Furthermore, a link between SCD activity and LDs has been observed in various cell lines cultured from goat mammary epithelial cells (Ren et al. 2018), mouse hepatocytes (Lounis et al. 2017) and human hepatoma cells (Lyn et al. 2014). Shi and colleague showed that SCD1-inhibited or -removal samples exhibited difficulties in LD formation (Shi et al. 2013). However, recent studies have revealed that the cytotoxic effects caused by the inhibition of FA synthesis can be reversed by exogenous FA supplementation. In particular, exogenous OA restored globally decreased levels of cell lipids in cells undergoing blockage of SCD activity, indicating that active lipid synthesis is required for the FA-mediated restoration of proliferation in SCD1inhibited cells (Hess et al. 2010). Regulators of LDs include the family of transcriptional regulators of lipid synthetic genes, known as SREBPs. In particular, the presence of SREBPs leads to an increase in LD proteins in fatty liver dystrophic mice (Hall et al. 2010). Several studies have also demonstrated a positive correlation between LD levels and SREBP1 expression (Pai et al. 2013, Fukunishi et al. 2014, Min et al. 2014).

The objective of the present study was to assess stagespecific LD profiles during early development of in vitro-produced porcine embryos and to associate these profiles with the mRNA levels of LD formation-related genes and with the effect of SCD1.

\section{Materials and methods}

\section{Ethics statement}

The experimental use of pigs was approved by the Institutional animal care and use committee, Seoul National University (SNU-140328-2).

\section{In vitro embryo production}

Mature oocytes were obtained using the method described in our previous study (Lee et al. 2016). Briefly, prepubertal gilt ovaries collected in Anseong, Kyunggi Province, Korea, were used in this experiment. The follicular fluid and cumulus-oocyte complexes (COCs) were aspirated using an 18-gauge needle and then pooled to obtain sediments. Sediments were washed with TL-HEPES-PVA medium, and oocytes with compact cumulus cells and granulated cytoplasm were selected for in vitro maturation. The washed COCs were cultured in a tissue culture medium (TCM-199; Life Technologies, Carlsbad, CA, USA) containing $10 \mathrm{ng} / \mathrm{mL}$ epidermal growth factor, $1 \mathrm{mg} / \mathrm{mL}$ insulin, and $10 \%$ porcine follicular fluid for $44 \mathrm{~h}$ at $39.8^{\circ} \mathrm{C}$ at $5 \% \mathrm{CO}_{2}$ and $100 \%$ humidity. The COCs were treated with $4 \mathrm{IU} / \mathrm{mL}$ of the hormones Q6 equine chorionic gonadotropin and human chorionic gonadotropin (Intervet, Cambridge, UK) for the first $22 \mathrm{~h}$. The COCs were then matured under hormonefree conditions. To generate parthenotes, cumulus-free oocytes were activated with an electric pulse $(1.0 \mathrm{kV} / \mathrm{cm}$ for $60 \mathrm{~ms})$ in activation medium $\left(280 \mathrm{mM}\right.$ mannitol, $0.01 \mathrm{mM} \mathrm{CaCl}{ }_{2}$, $0.05 \mathrm{mM} \mathrm{MgCl}$ ) using a BTX Electro-cell Manipulator (BTX, CA, USA), followed by $4 \mathrm{~h}$ of incubation in PZM3 medium containing $2 \mathrm{mmol} / \mathrm{L}$ 6-dimethylaminopurine. Subsequently, the zygotes were transferred in groups of 35-70 to wells with $500 \mu \mathrm{L}$ PZM3 medium for 7 days with or without DMSO, CAY10566 $(50 \mu \mathrm{M})$ or OA $(\mathrm{O} 1008,112-80-1,100 \mu \mathrm{M})$ from Sigma (purity, 99\%).

\section{Immunocytochemistry}

Each stage of embryos without zona pellucida was fixed in $4 \%$ paraformaldehyde for $30 \mathrm{~min}$ at $4^{\circ} \mathrm{C}$. Fixed samples were permeabilized using $1 \%$ Triton $\mathrm{X}-100$ for $5 \mathrm{~min}$ at room temperature and washed three times with phosphate-buffered saline (PBS). The embryos were blocked using $1 \%$ bovine serum albumin (BSA) in PBS for $1 \mathrm{~h}$ at room temperature, and primary antibodies targeting SCD1 (ab39969, rabbit-igG; Abcam) were added overnight at $4{ }^{\circ} \mathrm{C}$. The primary antibody was diluted 1:200 in PBS containing 1\% BSA. Embryos were washed three times with PBS containing $0.1 \%$ Tween-20 before incubation with the fluorescent-conjugated secondary antibodies antirabbit-IgG (green, 1:500, A11008; Invitrogen) and anti-rabbitIgG (red, 1:500, A11012; Invitrogen), which were diluted in a blocking solution, for $2 \mathrm{~h}$ at room temperature. The samples were washed three times with PBS containing $0.1 \%$ Tween20, and nuclei were stained using $0.1 \%$ Hoechst 33342 (Molecular Probes) for $10 \mathrm{~min}$. After washing three times with PBS, samples were mounted on a slide glass. Stained samples were visualized under a microscope (Eclipse TE2000-U; Nikon), and captured images were processed using a Nikon digital sight DS-L1.

\section{Nile Red staining}

A number of lipid dyes have been used to stain LDs in mammalian oocytes, including Nile Red and BODIPY 493/503 (Genicot et al. 2005, del Collado et al. 2016). Nile Red is commonly used for porcine and bovine oocytes that have large LDs (Leroy et al. 2005a, Sturmey et al. 2006). The Nile Red staining method of embryos is described elsewhere (Sudano et al. 2016). Briefly, a sample of each early denuded embryo development stage $(2-3,4,6-8$, morula and blastocyst (BL) stages) was randomly selected during the experimental replications and stained with Nile Red (Molecular Probes). Denuded embryos were washed in a solution of $0.1 \%$ polyvinylpyrrolidone in PBS (PVP-PBS) and fixed in $4 \%$ formaldehyde in PVP-PBS solution for $1 \mathrm{~h}$. A stock solution 
was prepared by dissolving Nile Red in dimethyl sulfoxide at a concentration of $1 \mathrm{mg} / \mathrm{mL}$ and stored at $20^{\circ} \mathrm{C}$. Embryos were stained with a working solution of $15 \mathrm{mg} / \mathrm{mL}$ of Nile Red in PVP-PBS solution for $1 \mathrm{~h}$ in the dark at room temperature. Final concentrations were obtained by diluting the stock with PVP-PBS. After washing three times with PBS, samples were mounted on a glass slide. Stained samples were visualized under a microscope for intensity (Eclipse TE2000-U; Nikon) and for size and number (confocal laser scanning microscope; Leica). Captured images were processed using the LAS $X$ Software and Nikon digital sight DS-L1. Fluorescence intensity and size were quantified using ImageJ 1.51j8 software (Wayne Rasband; National Institutes of Health, Washington DC, USA).

\section{Quantitative RT-PCR}

Pooled embryos, each stage of in vitro-produced embryos (2-3-cell, $n=20 ; 4$-cell, $n=20$; 6 -8-cell, $n=20$; morula, $n=10$; and $\mathrm{BL}, n=5)$, and single blastocysts were processed with Dynabeads mRNA DIRECT Kit (Invitrogen) following the manufacturer's instructions. The zona pellucida was removed using Tyroid's acid before mRNA extraction. cDNA was synthesized using a High-Capacity RNA-to-cDNA Kit (Applied Biosystems). Extracted cDNA samples were amplified using a DyNAmo HS SYBR Green qPCR Kit (Thermo Fisher Scientific) containing 1-2 pmol of each primer set listed in Table 1 in a $10 \mu \mathrm{L}$ reaction volume. Amplification and detection were conducted using the ABI 7300 Real-Time PCR system (Applied Biosystems) under the following conditions: one cycle of $50^{\circ} \mathrm{C}$ for $2 \mathrm{~min}$ and $95^{\circ} \mathrm{C}$ for $10 \mathrm{~min}$, followed by 40 cycles of denaturation at $95^{\circ} \mathrm{C}$ for $15 \mathrm{~s}$ and annealing/extension for $1 \mathrm{~min}$ (annealing/extension temperatures dependent on each primer set). The dissociation curves were analyzed, and the amplified products were loaded onto gels to confirm the specificity of the PCR products. The relative expression level was calculated by normalizing the threshold cycle $(\mathrm{Ct})$ values of each gene to that of the reference gene GAPDH via the delta-delta Ct method.

Table 1 Primer sequences used for real-time PCR.

\begin{tabular}{|c|c|c|c|}
\hline Genes & Sequences & AT $\left({ }^{\circ} \mathrm{C}\right)$ & $\begin{array}{l}\text { Size } \\
\text { (bp) }\end{array}$ \\
\hline SCD1 & $\begin{array}{l}\text { 5'-GCCACCTTTCTTCGTTACG-3' } \\
\text { 5'-CCTCACCCACACCTCCCAAT-3' }\end{array}$ & 60 & 142 \\
\hline SREBP-1C & $\begin{array}{l}\text { 5'-GCGAGTCAAGACCAGTCTCC-3' } \\
\text { 5'-TCCCCATCCACGAAGAAACG-3' }\end{array}$ & 60 & 156 \\
\hline ARF1 & $\begin{array}{l}\text { 5'-GGACCTTCCCAATGCCATGA-3' } \\
\text { 5'-GAGCTGATTGGACAGCCAGT-3' }\end{array}$ & 60 & 148 \\
\hline COPG2 & $\begin{array}{l}\text { 5'-GACGAGGAGTCTGGTAGTGG-3' } \\
\text { 5'-TTCTGTGGCTTCCGTAGTTCC-3' }\end{array}$ & 56 & 180 \\
\hline PLD1 & $\begin{array}{l}\text { 5'-CAGACACCACTTGCACAACG-3' } \\
\text { 5'-AACTTCGGATGGAGCCTGTG-3' }\end{array}$ & 56 & 188 \\
\hline$E R K 2$ & $\begin{array}{l}\text { 5'-CAAACCTTCCAACCTGCTGC-3' } \\
\text { 5'-TACTCCGTCAGGAACCCTGT-3' }\end{array}$ & 60 & 111 \\
\hline ACTB & $\begin{array}{l}\text { 5'-GTGGACATCAGGAAGGACCTCTA-3' } \\
\text { 5'-ATGATCTTGATCTTCATGGTGCT-3' }\end{array}$ & 63 & 131 \\
\hline
\end{tabular}

$\mathrm{AT}$, annealing temperature.

\section{Statistical analysis}

The data obtained in this study were analyzed using the GraphPad Prism statistical program (GraphPad Software). Data on developmental rates were arcsine-transformed and then analyzed using analysis of variance and the NewmanKeuls multiple comparison test. Relative transcription levels in embryos were analyzed using the unpaired Student's $t$-test. All data are expressed as the means \pm standard error of the mean. A probability of $P<0.05$ was considered statistically significant.

\section{Results}

\section{Identification of SCD1 mRNA and protein levels at different porcine embryo stages}

To avoid saturated FA stress, stearic acid is converted into mono-unsaturated OA by SCD. To determine the expression levels of SCD1 in different embryonic stages, SCD1 protein and mRNA levels were observed for all stages of embryos using immunocytochemistry staining and qRT-PCR, respectively. SCD1 protein expression was detected during embryogenesis (Fig. 1A). In addition, SCD1 protein expression had decreased
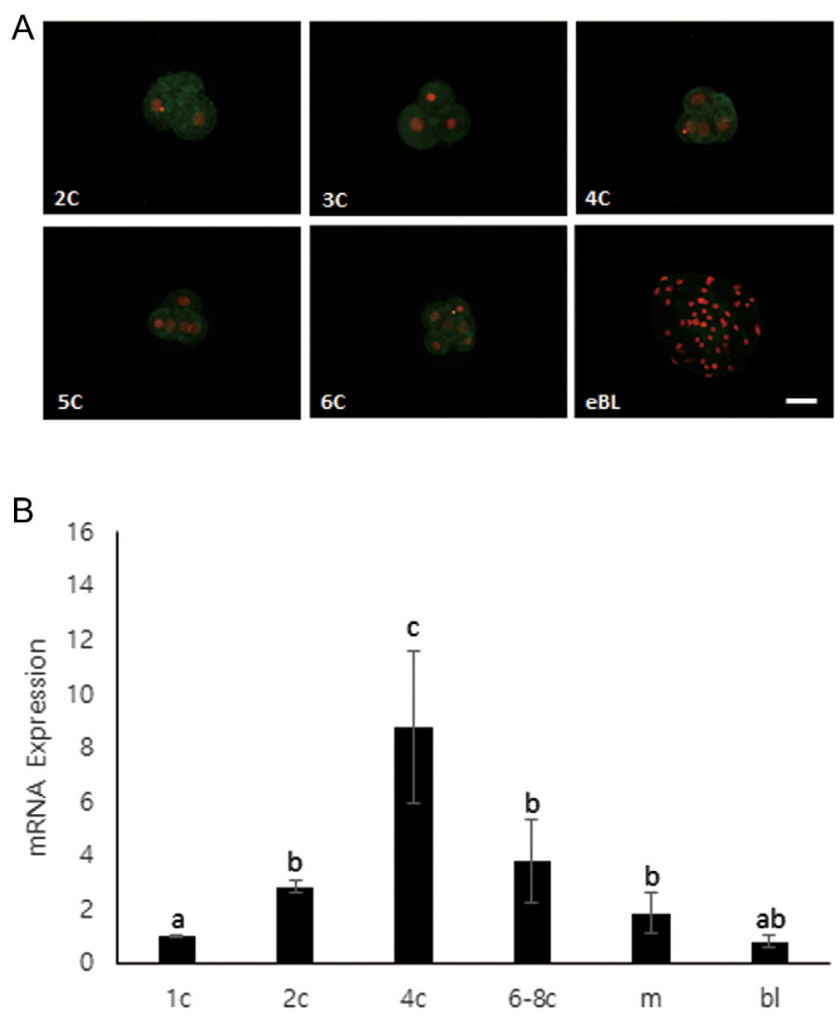

Figure 1 Changes in the SCD1 gene during porcine embryonic stages. Immunocytochemistry for SCD1 expression in different stages of in vitro-produced porcine embryos. The nuclei of embryos were counterstained with Hoechst 33342 (orange) (A). Real-time quantification of SCD1 expression in different embryonic stages (B). Different superscript letters indicate significant differences $(P<0.05)$. Scale bar: $100 \mu \mathrm{m}$. 
at the BL stage. Interestingly, the intensity of SCD1 protein level at the two-cell stage did not differ from the intensity at approximately the morulae embryonic stage. In addition, the SCD1 mRNA expression level was significantly higher at the four-cell stage and decreased gradually as the embryo developed (Fig. 1B).

\section{$O A$ rescues the effect of $S C D 1$ depletion}

To determine the importance of SCD1 in porcine embryo development, embryos were cultured either with or without CAY10566 during the entire culture period. OA had a positive effect on embryo development without toxicity at low concentration (Fig. 2A, B and C), similar to previous results (Aardema et al. 2011). As expected, inhibition of SCD1 had a detrimental effect on embryonic development (Fig. 2D). To confirm the role of OA in an SCD1-inhibited environment,
SCD1-inhibited embryos were treated with OA. Remarkably, the negative effects of exposure to CAY10566 were completely counteracted by simultaneous exposure to OA during development (Fig. 2E). The amount of SCD1 protein in each group was also examined (Fig. 2F). The intensity of SCD1 protein levels in each group indicated that the expression of SCD1 was reduced in the CAY10566 treatment group and that the expression of SCD1 was restored in the group supplemented with OA (Fig. 2G).

\section{Effect of SCD1 inhibition on lipid droplet formation-related genes}

Research has demonstrated that phospholipase D1 (PLD1) and extracellular signal-regulated kinase 2 (ERK2) are essential for the increased LD formation triggered by insulin stimulation (Andersson et al. 2006).
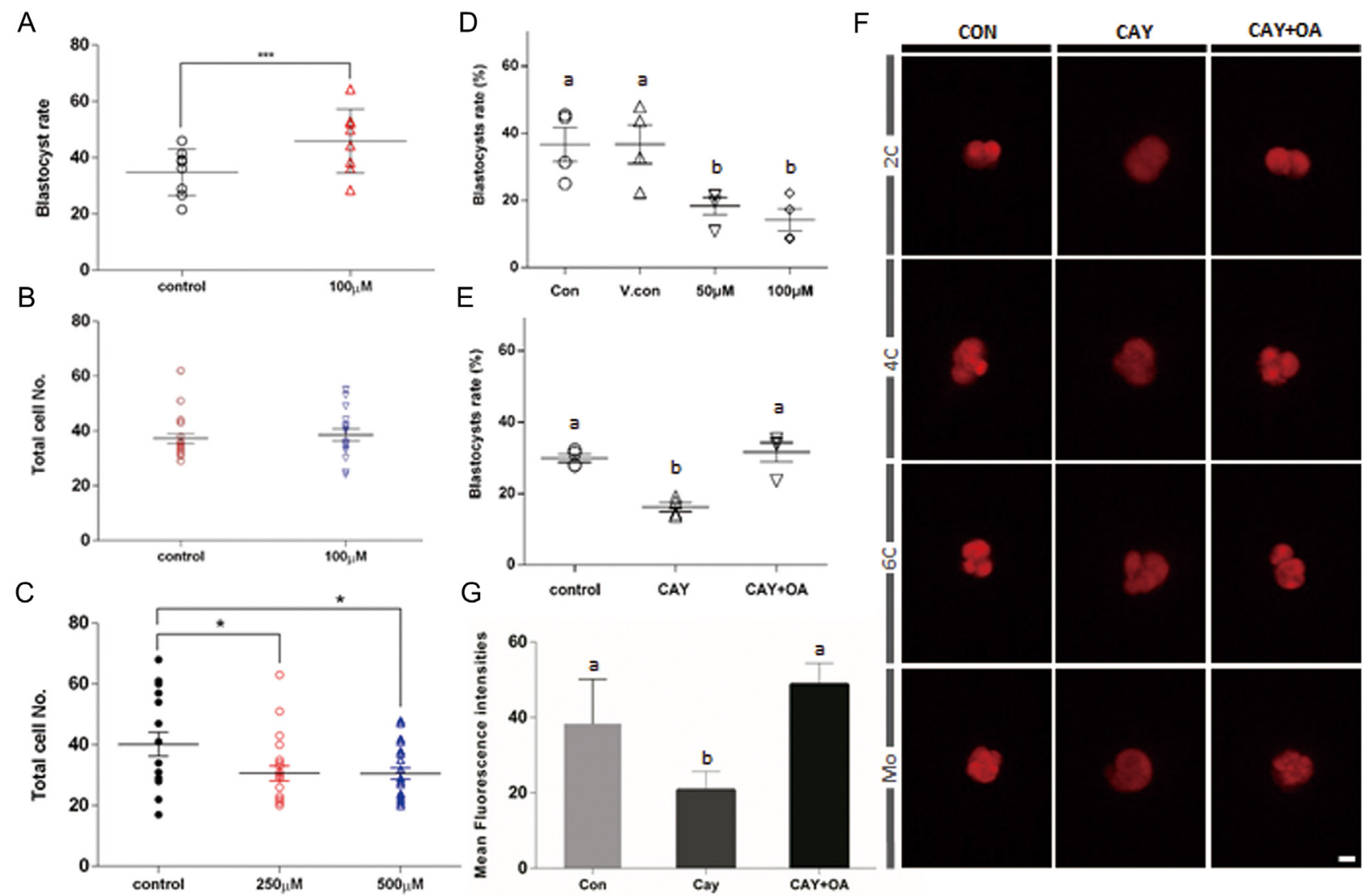

Figure 2 Effect of CAY10566 (SCD1 inhibitor) and oleic acid on embryos. Percentage of parthenogenetic embryo blastocyst rate were counted at day 7 of culture from embryos exposed to CAY10566, oleic acid (OA) and CAY10566 with OA treated simultaneously (168 h). Dose-dependent effect of oleic acid on blastocyst formation rate (A, B and C). Added $100 \mu \mathrm{M}$ of OA group showed an increase of embryo development rate without toxicity (A and B), but toxicity was confirmed at higher (250-500 $\mu \mathrm{M})$ concentrations (C). Dose-dependent effect of CAY10566 on blastocyst formation rate (D). Effect of oleic acid on CAY10566-treated parthenogenetic embryo blastocyst rate. Low concentration of CAY10566 has no effect on blastocyst rate (1-25 $\mu \mathrm{M}$, data not shown) (E). Protein levels of the SCD1 gene in each embryo stage (2C; 2cell, 4C; 4cell, 6C; 6cell, Mo; Morulae) (F) and mean fluorescence intensity of SCD1 (G). Different superscript letters indicate significant differences between the control (con), DMSO (vehicle control, V.con), CAY10566-treated (CAY) and CAY10566 + oleic acid (CAY + OA) groups $(P<0.05)$. DMSO was used only in CAY and OA was in liquid form. Scale bar: $100 \mu \mathrm{m}$. Each group has 3-4 replicates. 
The activity of ERK2 appears to be essential for the PLD1-mediated increase in LD formation. The abovementioned LD formation-related genes are lipogenic genes, and their expression is decreased by stress of the $E R$, which is directly connected to mitochondria in lipid synthesis (Marchi et al. 2014) caused by SCD1 deficiency (ALJohani et al. 2017). Based on these findings, we hypothesized that SCD1-inhibited embryos would have lower developmental potential as a result of their more deficient utilization of intracellular LDs compared to normal embryos. To investigate this possibility, we compared the above genes in SCD1-deficient, control and OA-addition treatments. As expected, SCD1inhibited embryos exhibited lower mRNA expression compared to normal embryos (Fig. 3A). In contrast,
mRNA expression in OA-treated embryos was higher than that in control group (Fig. 3B). In the group supplemented with OA, deficient gene expression due to SCD1 inhibition was restored to the level of normal embryos (Fig. 3C).

\section{Effect of SCD1 inhibition on lipid droplet formation}

We hypothesized that SCD1-inhibited embryos would have lower developmental potential as a result of their more deficient utilization of intracellular LDs compared to normal embryos. To confirm this hypothesis, normal, SCD1-inhibited and OA-supplemented embryos were stained with Nile Red, and confocal images were used to determine the size and number of LDs. Embryos

\section{A}
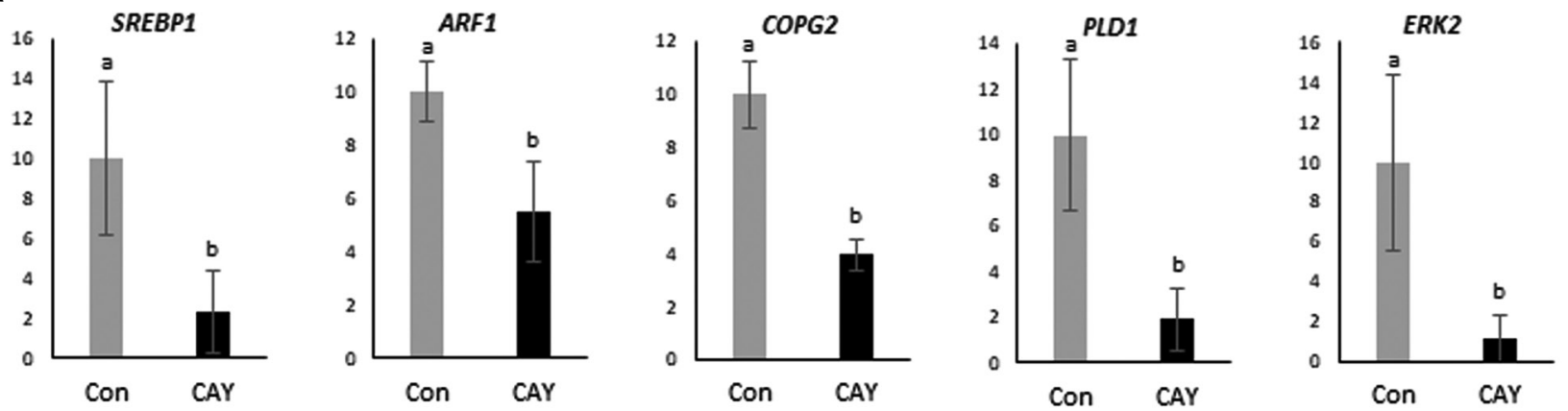

B
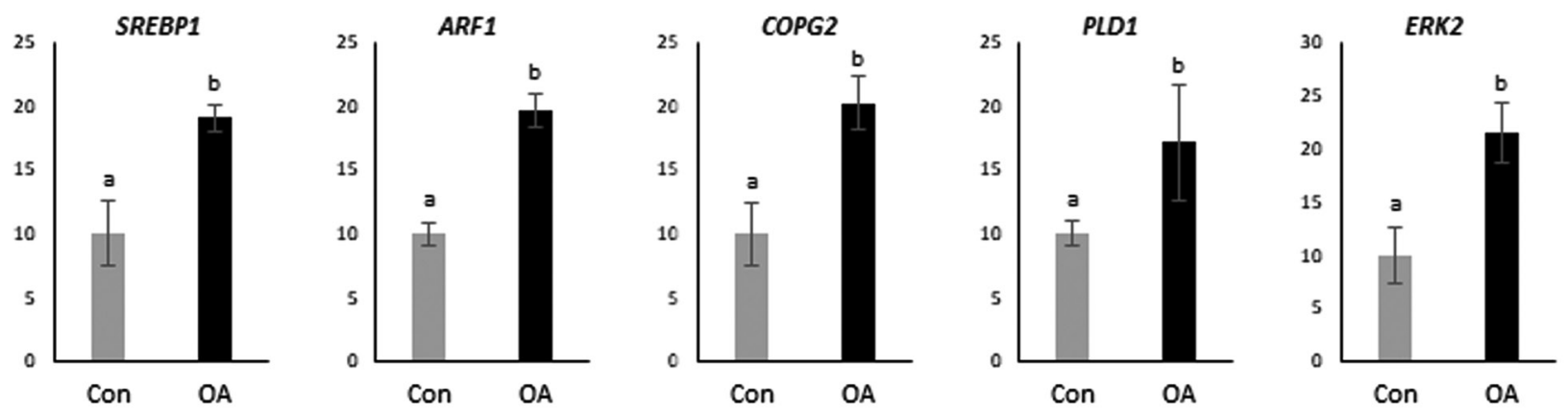

C
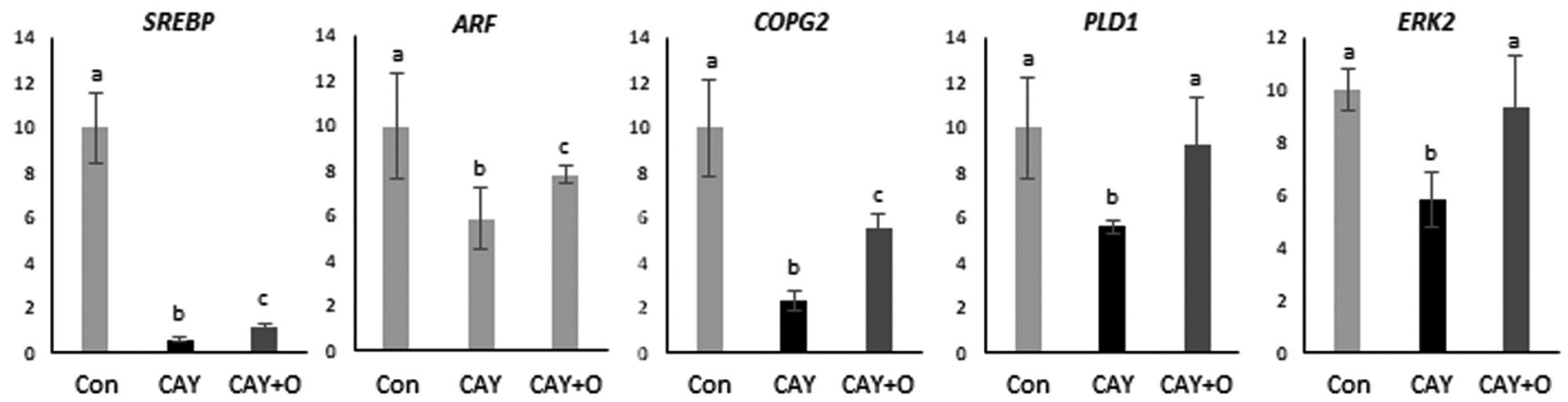

Figure 3 Transcription levels of lipid droplet formation-related genes. Transcription levels of lipid droplet formation-related genes shown for control SCD1-inhibited blastocysts (CAY10566) (A), oleic acid-treated group (B) and CAY10566 with oleic acid-treated blastocysts (C). Each group of blastocysts was pulled at day 7 after parthenogenesis. Each group has three replicates. Different superscript letters indicate significant differences between the control (CON), CAY10566-treated (CAY), oleic acid-treated (OA) and CAY10566 + oleic acid $(C A Y+O)$ groups $(P<0.05)$. 

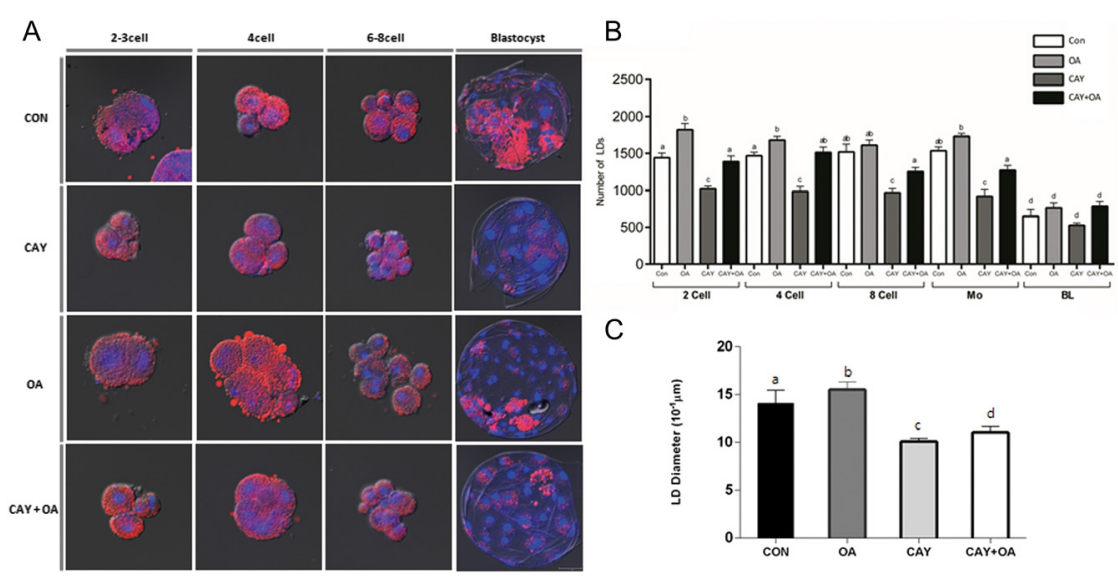

Figure 4 Lipid droplet formation of CAY10566and oleic acid-treated embryos. Porcine embryos at different stages stained with Hoechst 33342, fixed and observed under z-stack of confocal microscopy. Nile Red fluorescence indicating lipid droplets (A). Stage-dependent effect of CAY10566 and oleic acid on lipid droplet number (B). Lipid droplet size was calculated from (C). Different superscript letters indicate significant differences between the control (CON), oleic acid- (OA), CAY10566- (CAY) and CAY10566 + oleic acid-treated groups $(\mathrm{CAY}+\mathrm{OA})(P<0.05)$. Scale bar: $50 \mu \mathrm{m}$. from the three treatments differed significantly in the size and number of LDs. When embryos were exposed to $\mathrm{OA}$, the number of LDs increased, whereas in the simultaneous presence of a SCD1 inhibitor, the number of LD was drastically reduced (Fig. 4A and B). However, the number of LDs at the BL stage did not differ among treatments (Fig. 4B). We observed an increase in the size and number of LDs in OA-supplemented embryos following the same pattern as the previously described transcription levels (Fig. 4C).

\section{Discussion}

In embryo development, several potential problems are related to embryonic metabolism, and once failure occurs, damage to the embryo is difficult to reverse. For these reasons, a balance is necessary between the energy production required for embryonic development and the rate at which that energy will be used. Lipids serve as signaling molecules that contribute to key events during embryonic development, implantation and post-implantation growth (Burnum et al. 2009). However, elements of additions to media regarding lipid metabolism content or FA composition have been rarely reported.

\section{The role of SCD1 in embryo development}

To understand the importance of SCD1 in pig embryo development, we examined the effect of the inhibition of SCD1 in embryos on LD formation, which plays an important role in embryonic development. In bovine specimens, SCD activity in cumulus cells appears to be a prerequisite for a functional and protective barrier of cumulus cells that prevents negative effects of saturated FAs on the developmental competence of the oocyte (Aardema et al. 2017). Indeed, mice that are genetically deficient for SCD1 are resistant to diet-induced weight gain and hepatic steatosis and demonstrate increased insulin sensitivity (Miyazaki et al. 2007, Ntambi et al. 2002). Mice lacking SCD1 are lean and resistant to diet-induced obesity (Flowers \& Ntambi 2008, Ntambi et al. 2002). Moreover, they exhibit reduced FA and TAG synthesis in response to high dietary carbohydrates (Miyazaki et al. 2004) and also have increased fat oxidation rates in various tissues (Flowers \& Ntambi 2008). The present report demonstrates that SCD1 activity in porcine embryos is important for embryo development. More specifically, during embryonic development, SCD1-depleted groups exhibited less morula compaction than during normal embryo development (Table 2). This result supports previous reports regarding the timing of lipid source use during embryo development (Cui et al. 2007). In addition, our findings confirm that FA oxidation is correlated with oxygen consumption by the embryo, which remains relatively constant up to the eight-cell stage, but suddenly increases between the eight-cell and morula stages in humans (Haggarty et al. 2006). However, the concentration of CAY10566 used in our study was higher than the previously reported concentrations of CAY10566 required for SCD1 inhibition, likely because more lipid metabolism-related substances occur in the cytoplasm of pig embryos compared to other

Table 2 In vitro development of SCD1-inhibited embryos.

\begin{tabular}{lcccc}
\hline Group & No. embryos $(n=3)$ & No. cleaved $(\%)^{\S}$ & No. Mo-compaction $(\%)^{\mathrm{F}}$ & Blastocyst $(\%)$ \\
\hline CON & 125 & $99(79.3 \pm 1.3)$ & $50(39.9 \pm 1.4)^{\mathrm{a}}$ & $43(34.9 \pm 3.1)^{\mathrm{a}}$ \\
V.con & 123 & $95(76.9 \pm 2.1)$ & $45(37.4 \pm 4.0)^{\mathrm{a}}$ & $42(34.3 \pm 1.1)^{\mathrm{a}}$ \\
$50 \mu \mathrm{M}$ & 133 & $102(77.7 \pm 3.7)$ & $16(11.6 \pm 1.7)^{\mathrm{b}}$ & $13(9.9 \pm 1.7)^{\mathrm{b}}$ \\
$100 \mu \mathrm{M}$ & 125 & $92(73.6 \pm 2.8)$ & $12(9.6 \pm 1.2)^{\mathrm{b}}$ & $8(6.4 \pm 1.5)^{\mathrm{b}}$ \\
\hline
\end{tabular}

${ }^{\S}$ The cleavage rate was counted after 2 days in culture; ${ }^{\mathrm{F}}$ the morula (Mo) compaction rate was counted after 4 days in culture. The blastocyst rate was counted after 7 days in culture. Values with different letters ( $a$ and b) are significantly different $(P<0.05)$. 
species and are possibly more complementary to the metabolism-related substances present in the culture medium. Nevertheless, our results clearly demonstrate that the depletion of SCD1 adversely affects pig embryo development similar to results observed for other species.

\section{Correlation between SCD1 and lipid droplet formation}

Triacylglycerides and cholesteryl esters are stored in LDs, which are highly ordered intracellular structures that are formed from the ER through a budding process. An abnormal status of the $S C D 1$ gene negatively affects this process (Farese \& Walther 2009). A link between SCD activity and lipid droplet size was previously observed in cell lines cultured from patients with Berardinelli-Seip congenital lipodystrophy (Boutet et al. 2009). This study showed that patients with mutations in the Seipin gene had increased the percentage of saturated fatty acid in their lipids, reducing SCD activity and decreasing the size and amount of LD.

\section{Role of $\mathrm{OA}$ in porcine preimplantation embryo}

Mammalian oocytes and embryos efficiently incorporate and metabolize external FAs. Previous studies have observed that embryos are capable of taking up FAs from the environment (Roche 2006, Fouladi-Nashta et al. 2007). However, our data indicate that lipid uptake occurs during an earlier stage (Fig. 2). Therefore, it is possible that FA exposure directly influences the embryo rather than indirectly affecting granulosa and cumulus cells (Mu et al. 2001, Leroy et al. 2005b). The amount and size of LDs in the embryos in our experiment changed after exposure to OA during embryo development. This finding suggests that exogenous FAs directly positively affect embryos. However, the effects on LDs in embryos largely depended on the type and concentration of FAs to which the embryos were exposed during development. In bovines, saturated FAs negatively affected embryo development and LD size (Aardema et al. 2011). In our experiments, MUFAs also had a negative effect on embryo development at high concentrations. The developmental rate of blastocysts increased with increasing MUFA concentration, but the blastocyst cell number decreased at high concentrations (Fig. 2). Accordingly, unsaturated FA content may be an important factor in preimplantation embryo development. OA, the product of SCD1 activity, was shown to compete with the saturated FAs, block the abnormal lipid distribution and attenuate ER stress (Hapala et al. 2011, Peng et al. 2011). Remarkably, exogenous supplementation of OA, the direct product of SCD1 activity and rescued the developmental ability (Fig. 2). These data indicate that SCD1 is required for early embryonic development in pig.

\section{Summary}

We provide a comprehensive outline of LD formation and its effects on early porcine embryo development. These results are consistent with the general LD formation process of mammals. Our findings reveal that porcine embryos require $\mathrm{OA}$ for their development and are thus sensitive to SCD1 inhibition, which activates a cascade of events that negative effect on porcine embryo development.

\section{Declaration of interest}

The authors declare that there is no conflict of interest that could be perceived as prejudicing the impartiality of the research reported.

\section{Funding}

This work did not receive any specific grant from any funding agency in the public, commercial, or not-for-profit sector.

\section{Acknowledgements}

This work was supported by BK21 Plus Program and Korea Institute of Planning and Evaluation for Technology in food, agriculture, forestry and fisheries (IPET) through Development of high value-added food technology program funded by Ministry of agriculture, food and rural affairs (MAFRA, 118042-03-1-HD020).

\section{References}

Aardema H, Vos PL, Lolicato F, Roelen BA, Knijn HM, Vaandrager AB, Helms JB \& Gadella BM 2011 Oleic acid prevents detrimental effects of saturated fatty acids on bovine oocyte developmental competence. Biology of Reproduction 85 62-69. (https://doi.org/10.1095/ biolreprod.110.088815)

Aardema H, van Tol HTA, Wubbolts RW, Brouwers J, Gadella BM \& Roelen BAJ 2017 Stearoyl-CoA desaturase activity in bovine cumulus cells protects the oocyte against saturated fatty acid stress. Biology of Reproduction 96 982-992. (https://doi.org/10.1095/ biolreprod.116.146159)

Acton BM, Jurisicova A, Jurisica I \& Casper RF 2004 Alterations in mitochondrial membrane potential during preimplantation stages of mouse and human embryo development. Molecular Human Reproduction 10 23-32. (https://doi.org/10.1093/molehr/gah004)

ALJohani AM, Syed DN \& Ntambi JM 2017 Insights into stearoylCoA desaturase-1 regulation of systemic metabolism. Trends in Endocrinology and Metabolism 28 831-842. (https://doi.org/10.1016/j. tem.2017.10.003)

Andersson L, Bostrom P, Ericson J, Rutberg M, Magnusson B, Marchesan D, Ruiz M, Asp L, Huang P, Frohman MA et al. 2006 PLD1 and ERK2 regulate cytosolic lipid droplet formation. Journal of Cell Science $\mathbf{1 1 9}$ 2246-2257. (https://doi.org/10.1242/jcs.02941)

Beller M, Sztalryd C, Southall N, Bell M, Jackle H, Auld DS \& Oliver B 2008 COPI complex is a regulator of lipid homeostasis. PLoS Biology 6 2530-2549.

Boutet E, El Mourabit H, Prot M, Nemani M, Khallouf E, Colard O, Maurice M, Durand-Schneider AM, Chretien Y, Gres S et al. 2009 Seipin deficiency alters fatty acid Delta9 desaturation and lipid droplet formation in Berardinelli-Seip congenital lipodystrophy. Biochimie 91 796-803. (https://doi.org/10.1016/j.biochi.2009.01.011) 
Burnum KE, Cornett DS, Puolitaival SM, Milne SB, Myers DS, Tranguch S, Brown HA, Dey SK \& Caprioli RM 2009 Spatial and temporal alterations of phospholipids determined by mass spectrometry during mouse embryo implantation. Journal of Lipid Research 50 2290-2298. (https:// doi.org/10.1194/jlr.M900100-JLR200)

Cui XS, Li XY, Shen XH, Bae YJ, Kang JJ \& Kim NH 2007 Transcription profile in mouse four-cell, morula, and blastocyst: genes implicated in compaction and blastocoel formation. Molecular Reproduction and Development 74 133-143. (https://doi.org/10.1002/mrd.20483)

del Collado M, Saraiva NZ, Lopes FL, Gaspar RC, Padilha LC, Costa RR, Rossi GF, Vantini R \& Garcia JM 2016 Influence of bovine serum albumin and fetal bovine serum supplementation during in vitro maturation on lipid and mitochondrial behaviour in oocytes and lipid accumulation in bovine embryos. Reproduction Fertility and Development 28 1721-1732. (https://doi.org/10.1071/RD15067)

Dumollard R, Campbell K, Halet G, Carroll J \& Swann K 2008 Regulation of cytosolic and mitochondrial ATP levels in mouse eggs and zygotes. Developmental Biology 316 431-440. (https://doi.org/10.1016/j. ydbio.2008.02.004)

Dunning KR, Cashman K, Russell DL, Thompson JG, Norman RJ \& Robker RL 2010 Beta-oxidation is essential for mouse oocyte developmental competence and early embryo development. Biology of Reproduction 83 909-918. (https://doi.org/10.1095/biolreprod.110.084145)

Farese RV \& Walther TC 2009 Lipid droplets finally get a little R-E-S-P-EC-T. Cell 139 855-860. (https://doi.org/10.1016/j.cell.2009.11.005)

Flowers MT \& Ntambi JM 2008 Role of stearoyl-coenzyme A desaturase in regulating lipid metabolism. Current Opinion in Lipidology 19 248-256. (https://doi.org/10.1097/MOL.0b013e3282f9b54d)

Fouladi-Nashta AA, Gutierrez CG, Gong JG, Garnsworthy PC \& Webb R 2007 Impact of dietary fatty acids on oocyte quality and development in lactating dairy cows. Biology of Reproduction 77 9-17. (https://doi. org/10.1095/biolreprod.106.058578)

Fukunishi S, Sujishi T, Takeshita A, Ohama H, Tsuchimoto Y, Asai A, Tsuda Y \& Higuchi K 2014 Lipopolysaccharides accelerate hepatic steatosis in the development of nonalcoholic fatty liver disease in Zucker rats. Journal of Clinical Biochemistry and Nutrition 54 39-44. (https:// doi.org/10.3164/jcbn.13-49)

Genicot G, Leroy JLMR, Van Soom A \& Donnay I 2005 The use of a fluorescent dye, Nile red, to evaluate the lipid content of single mammalian oocytes. Theriogenology 63 1181-1194. (https://doi. org/10.1016/j.theriogenology.2004.06.006)

Guo Y, Walther TC, Rao M, Stuurman N, Goshima G, Terayama K, Wong JS, Vale RD, Walter P \& Farese RV 2008 Functional genomic screen reveals genes involved in lipid-droplet formation and utilization. Nature 453 657-661. (https://doi.org/10.1038/nature06928)

Haggarty P, Wood M, Ferguson E, Hoad G, Srikantharajah A, Milne E, Hamilton M \& Bhattacharya S 2006 Fatty acid metabolism in human preimplantation embryos. Human Reproduction 21 766-773. (https:// doi.org/10.1093/humrep/dei385)

Hall AM, Brunt EM, Chen ZJ, Viswakarma N, Reddy JK, Wolins NE \& Finck BN 2010 Dynamic and differential regulation of proteins that coat lipid droplets in fatty liver dystrophic mice. Journal of Lipid Research $\mathbf{5 1}$ 554-563. (https://doi.org/10.1194/jlr.M000976)

Hapala I, Marza E \& Ferreira T 2011 Is fat so bad? Modulation of endoplasmic reticulum stress by lipid droplet formation. Biology of the Cell 103 271-285. (https://doi.org/10.1042/BC20100144)

Hess D, Chisholm JW \& Igal RA 2010 Inhibition of stearoylCoA desaturase activity blocks cell cycle progression and induces programmed cell death in lung cancer cells. PLoS ONE 5 e11394. (https://doi.org/10.1371/ journal.pone.0011394)

Hsieh K, Lee YK, Londos C, Raaka BM, Dalen KT \& Kimmel AR 2012 Perilipin family members preferentially sequester to either triacylglycerol-specific or cholesteryl-ester-specific intracellular lipid storage droplets. Journal of Cell Science 125 4067-4076. (https://doi.org/10.1242/jcs.104943)

Lee DK, Park CH, Choi KH, Jeong YI, Uh KJ, Hwang JY, Lee SG \& Lee CK 2016 Aggregation of cloned embryos in empty zona pellucida improves derivation efficiency of pig ES-like cells. Zygote 24 909-917. (https://doi. org/10.1017/S0967199416000241)

Leese HJ 2012 Metabolism of the preimplantation embryo: 40 years on. Reproduction 143 417-427. (https://doi.org/10.1530/REP-11-0484)

Leroy JL, Genicot G, Donnay I \& Van Soom A 2005a Evaluation of the lipid content in bovine oocytes and embryos with nile red: a practical approach. Reproduction in Domestic Animals 40 76-78. (https://doi. org/10.1111/j.1439-0531.2004.00556.x)

Leroy JLMR, Vanholder T, Mateusen B, Christophe A, Opsomer G, de Kruif A \& Van Soom A 2005b Non-esterified fatty acids in follicular fluid of dairy cows and their effect on developmental capacity of bovine oocytes in vitro. Reproduction 130 485-495. (https://doi.org/10.1530/ rep.1.00735)

Lounis MA, Bergeron KF, Burhans MS, Ntambi JM \& Mounier C 2017 Oleate activates SREBP-1 signaling activity in SCD1-deficient hepatocytes. American Journal of Physiology-Endocrinology and Metabolism 313 E710-E720. (https://doi.org/10.1152/ajpendo.00151.2017)

Lyn RK, Singaravelu R, Kargman S, O'Hara S, Chan H, Oballa R, Huang Z, Jones DM, Ridsdale A, Russell RS et al. 2014 Stearoyl-CoA desaturase inhibition blocks formation of hepatitis C virus-induced specialized membranes. Scientific Reports 4 4549. (https://doi.org/10.1038/ srep04549)

Marchi S, Patergnani S \& Pinton P 2014 The endoplasmic reticulummitochondria connection: one touch, multiple functions. Biochimica et Biophysica Acta 1837 461-469. (https://doi.org/10.1016/j. bbabio.2013.10.015)

Min B, Lee H, Song JH, Han MJ \& Chung J 2014 Arctiin inhibits adipogenesis in 3T3-L1 cells and decreases adiposity and body weight in mice fed a high-fat diet. Nutrition Research and Practice 8 655-661. (https://doi.org/10.4162/nrp.2014.8.6.655)

Miyazaki M, Dobrzyn A, Man WC, Chu KK, Sampath H, Kim HJ \& Ntambi JN 2004 Stearoyl-CoA desaturase 1 gene expression is necessary for fructose-mediated induction of lipogenic gene expression by sterol regulatory element-binding protein-1c-dependent and -independent mechanisms. Journal of Biological Chemistry 279 25164-25171. (https:// doi.org/10.1074/jbc.M402781200)

Miyazaki M, Flowers MT, Sampath H, Chu K, Otzelberger C, Liu X \& Ntambi JM 2007 Hepatic stearoyl-CoA desaturase-1 deficiency protects mice from carbohydrate-induced adiposity and hepatic steatosis. Cell Metabolism 6 484-496. (https://doi.org/10.1016/j. cmet.2007.10.014)

Mu YM, Yanase T, Nishi Y, Tanaka A, Saito M, Jin CH, Mukasa C, Okabe T, Nomura M, Goto K et al. 2001 Saturated FFAs, palmitic acid and stearic acid, induce apoptosis in human granulosa cells. Endocrinology 142 3590-3597. (https://doi.org/10.1210/endo.142.8.8293)

Ntambi JM, Miyazaki M, Stoehr JP, Lan H, Kendziorski CM, Yandell BS, Song Y, Cohen P, Friedman JM \& Attie AD 2002 Loss of stearoylCoA desaturase-1 function protects mice against adiposity. PNAS 99 11482-11486. (https://doi.org/10.1073/pnas.132384699)

Pai WY, Hsu CC, Lai CY, Chang TZ, Tsai YL \& Her GM 2013 Cannabinoid receptor 1 promotes hepatic lipid accumulation and lipotoxicity through the induction of SREBP-1c expression in zebrafish. Transgenic Research 22 823-838. (https://doi.org/10.1007/s11248-012-9685-0)

Peng G, Li L, Liu Y, Pu J, Zhang S, Yu J, Zhao J \& Liu P 2011 Oleate blocks palmitate-induced abnormal lipid distribution, endoplasmic reticulum expansion and stress, and insulin resistance in skeletal muscle. Endocrinology 152 2206-2218. (https://doi.org/10.1210/en.2010-1369)

Ren CF, Wang LZ, Fan YX, Jia RX, Zhang GM, Deng MT, Deng KP \& Wang F 2018 Scd1 contributes to lipid droplets formation in GMEC via transcriptional regulation of Tip47 and Adrp. European Journal of Lipid Science and Technology 120 1700238. (https://doi.org/10.1002/ ejlt.201700238)

Roche JF 2006 The effect of nutritional management of the dairy cow on reproductive efficiency. Animal Reproduction Science 96 282-296. (https://doi.org/10.1016/j.anireprosci.2006.08.007)

Shi X, Li J, Zou XJ, Greggain J, Rodkaer SV, Faergeman NJ, Liang B \& Watts JL 2013 Regulation of lipid droplet size and phospholipid composition by stearoyl-CoA desaturase. Journal of Lipid Research $\mathbf{5 4}$ 2504-2514. (https://doi.org/10.1194/jlr.M039669)

Sturmey RG, O'Toole PJ \& Leese HJ 2006 Fluorescence resonance energy transfer analysis of mitochondrial: lipid association in the porcine oocyte. Reproduction 132 829-837. (https://doi.org/10.1530/REP-06-0073)

Sturmey RG, Reis A, Leese HJ \& McEvoy TGE 2009 Role of fatty acids in energy provision during oocyte maturation and early embryo development. Reproduction in Domestic Animals 44 (Supplement 3) 50-58. (https://doi.org/10.1111/j.1439-0531.2009.01402.x)

Sudano MJ, Rascado TD, Tata A, Belaz KR, Santos VG, Valente RS, Mesquita FS, Ferreira CR, Araujo JP, Eberlin MN et al. 2016 Lipidome 
signatures in early bovine embryo development. Theriogenology 86472 . e471-484.e471.

Thiam AR, Farese RV Jr \& Walther TC 2013 The biophysics and cell biology of lipid droplets. Nature Reviews Molecular Cell Biology 14 775-786. (https://doi.org/10.1038/nrm3699)

Walther TC \& Farese RV Jr 2012 Lipid droplets and cellular lipid metabolism. Annual Review of Biochemistry 81 687-714. (https://doi. org/10.1146/annurev-biochem-061009-102430)

Wilfling F, Wang HJ, Haas JT, Krahmer N, Gould TJ, Uchida A, Cheng JX, Graham M, Christiano R, Frohlich F, et al. 2013 Triacylglycerol synthesis enzymes mediate lipid droplet growth by relocalizing from the ER to lipid droplets. Developmental Cell 24 384-399. (https://doi. org/10.1016/j.devcel.2013.01.013)
Wolins NE, Quaynor BK, Skinner JR, Schoenfish MJ, Tzekov A \& Bickel PE 2005 S3-12, Adipophilin, and TIP47 package lipid in adipocytes. Journal of Biological Chemistry 280 19146-19155. (https://doi.org/10.1074/jbc. M500978200)

Received 25 October 2018

First decision 16 November 2018

Revised manuscript received 4 December 2018

Accepted 21 December 2018 